\title{
On the value of the brightness of spectral colours with different absolute intensity
}

\section{A. König \& R. Ritter}

To cite this article: A. König \& R. Ritter (1892) On the value of the brightness of spectral colours with different absolute intensity, Philosophical Magazine Series 5, 33:205, 541-542, DOI: $10.1080 / 14786449208620297$

To link to this article: http://dx.doi.org/10.1080/14786449208620297

曲 Published online: 08 May 2009.

Submit your article to this journal $\lceil\pi$

Џ Article views: 2

Q View related articles $₫$ 


\section{$\left[\begin{array}{ll}541 & ]\end{array}\right.$}

\section{Intelligence and Miscellaneous Articles.}

\section{ON THE VALUE OF THE BRIGHTNESS OF SPECTRAL COLOURS WITH DIFFERENT ABSOLUTE INTENSITY. BY A. KÖNIG AND R. RITTER.}

T PURKINJE was the first to point out that the relative bright- ness of different pigments was unequally influenced by a change in the intensity of their illuminations. In twilight blue is brighter than red, even though for mean illumination both colours seem to be equal. Dove and Seebeck subsequently pursued the phenomenon more minutely, and von Helmholtz found that it was also to be observed with spectral colours. If two differently coloured fields have the same brightness for mean illumination, then, after equal diminution in the objective intensity of both, that field which is illuminated by light of short wave-length will be the brighter, while after an increase of the intensity the longer wave-length seems brighter. Some years ago Brodhun * investigated this " Purkinje's phenomenon" quantitatively, and found that with the illuminations he used it could no longer be observed at higher limits; that is to say, that beyond a certain illumination all colours alter their relative brightness to the same extent when their objective intensity is increased to the same extent. Only at this illumination are we entitled to represent by a curve the distribution of intensity in the spectrum without any special statement as to the illumination at which the comparisons are made. Brodhun has made and published such curves for my own eyes (normal trichromatic), for his own (green-blind), and for Ritter's (red-blind).

It is, however, apparent that curves of the distribution of brightness in the spectrum can be obtained for each degree of brightness; they possess then no value unless at the same time the degree of brightness is given in such a way that the curve can be reconstructed.

In a comprehensive research, of only a small portion of which I here give an account + , R. Ritter and I have endeavoured to obtain such curves for our own eyes, and for those of some other observers, at very different brightnesses. In the change of form of these curves with increasing absolute intensity, Purkinje's phenomenon must of course come out, so that with increasing brightness the ordinates increase the more, the longer is the wave-length of the spectrum-light in question; by this the maximum is displaced in the direction of the red end.

* E. Brodhun, Beiträge zur Farbenlehre: Inaugural diss., Berlin 1887.

$\dagger$ A. König, "Ueber den Helligkeitswerth der Spectralfarben bei verschiedener absoluter Intensitäi." In Beiträge zur Psychologie und Physiologie der Sinnesorgane, von Helmholtz-Festschrift : Hamburg and Leipzig, 1891 (Leopold Voss).

Phil. Mag. S. 5. Vol, 33. No. 205. June 1892. 20 
The observation was made so that a surface which contained light of the wave-length $535 \mu \mu$ (thallium green) was always kept unaltered, and then the quantity of light expressed in breadths of the slit was determined which was necessary to attain the same brightness with the various wave-lengths of the spectrum in question. The reciprocal of this breadth of slit I call the value of the brightness of the spectral light examined for the given illumination.

The lowest degree of illumination was very near the lower limit of excitation, it was so feeble that the observer had to be at least a quarter of an hour in absolute darkness to perceive it at all. If we call the quantity of light 1 , which was necessary to prodnce this brightness in the standard green field, the other shades of brightness used are given by the quautities of light $16,256,1024$, $4096,16384,65336$, and 262144 . The last degree corresponds about for my eye to the illumination under which a white paper, lighted with 600 candles at a distance of a metre, appears when I view it through a diaphragm of 19 millim. aperture.

The principal results obtained by the various observers may be summed up in the following statements, in which all data refer to the dispersion spectrum of gas-light:-

1. For all observers (two trichromatic, a green-blind, and a redblind) the curve for the values of brightness had almost exactly the same form for the darkest shade, and it was that which has been observed by Donders, Hering, Dieterici, and myself for greater shades of brightness in congenital monochromasy. Its maximum was at about $535 \mu \mu$.

2. As the brightness increases the maximum increases with trichromatic persons, at first slowly, then more rapidly, and at length very slowly again. In the highest shade used it is about $610 \mu \mu$.

3. So far as the observations extend, green-blind persons exhibit the same phenomena as the trichromates.

4. With red-blind persons the maximum moves at first towards the long wave-length, but with mean illumination attains the wave-length $570 \mu \mu$, and remains here stationary for higher shades also, so far as the observations extend.

The statement in (1) was foreseen by Mr. E. Hering and the adherents of his theory, and was also observed shortly before the publication of our investigations. But that we are not justified in seeing in it a proof of the correctness of this theory follows from the observation, also made simultaneously by myself, that the distribution of brightness in the spectrum in individual cases is also unchanged, when by certain pathological processes the real sensation of colour is completely lost and only the sensation blackgrey-white remains.-Wiedemann's Annalen, No. 3, 1892. 